\title{
An exceptional occurrence of deep-sea sponges in the region of former Larsen Ice Shelves, Antarctic Peninsula, with the description of two new species
}

\author{
Daniel Buskowiak $^{1}$ (D) Dorte Janussen ${ }^{1}$ \\ Received: 1 June 2020 / Revised: 21 October 2020 / Accepted: 22 October 2020 / Published online: 12 January 2021 \\ (C) The Author(s) 2020
}

\begin{abstract}
Two new species of deep-sea sponges from the Weddell Sea are described. Both are new to science: a carnivorous Demospongiae species Abyssocladia antarctica sp. nov. and a Hexactinellida species Caulophacus leonieae sp. nov., the latter characterized by a new type of microscleres. Both were sampled at the former Larsen Ice Shelf region, Antarctic Peninsula, that was covered by ice until recent breakup events started in 1995. Abyssocladia Lévi, 1964 and Caulophacus Schulze, 1886 are well-known genera in the deep sea but were discovered here at only 200-300 m depths. The findings support the hypothesis that deep-sea and sub-shelf environments provide similar life conditions. These discoveries should urge us to further investigate areas of disintegrated Antarctic shelf ice as soon as possible, since new trophic conditions may have a severe impact on biodiversity and faunal composition.
\end{abstract}

Keywords Antarctic Ocean $\cdot$ Marine fauna $\cdot$ New species $\cdot$ Hexactinellida $\cdot$ Carnivorous sponges $\cdot$ Caulophacus $\cdot$ Abyssocladia

\section{Introduction}

A demosponge specimen of the genus Abyssocladia Lévi, 1964 was collected during the ANT-XXIII/8 expedition (23.11.2006-30.01-2007) by RV POLARSTERN in the Antarctic Weddell Sea. (Fig. 1a). Due to the collapse of Larsen AB ice-shelves, it became possible to conduct research in this shelf region that has been covered by ice for at least hundreds of years (Scambos et al. 2000). This expedition aimed to find answers to changes in biodiversity in the benthic life as well as other direct effects of the ice-

This article is registered in ZooBank under http://zoobank.org/ 2D3F17A7-1732-4575-9925-84E343022B2E

Communicated by M. Klautau

Daniel Buskowiak

daniel.buskowiak@stud.uni-frankfurt.de

Dorte Janussen

dorte.janussen@senckenberg.de

1 Senckenberg Research Institute and Nature Museum, Senckenberganlage 25, 60325 Frankfurt am Main, Germany shelf disintegration process. The scientific programme included taxonomic, physiological and genetic research as well as trophic interactions and pollution. It contributed to the "Census of Antarctic Marine Life" (CAML) and to the "Convention on the Conservation of Antarctic Marine Living Resources" (CCAMLR) (Gutt et al. 2011). The Porifera programme in particular aimed to investigate the diversity and abundance of the sponge fauna in the previously ice-covered Larsen $\mathrm{AB}$ region and compare it to the sponge fauna of Antarctic shelf regions still largely unaffected by ice-shelf disintegration, including biodiversity hotspot areas in the eastern Weddell Sea (Gutt 2008; Gutt et al. 2011).

A hexactinellid sponge specimen of the genus Caulophacus Schulze, 1886 was collected during ANTXXVII/3 (8.0218.04.2011) to the Antarctic Peninsula and across the Weddell Sea (Fig. 1b). The scientific programme of this expedition was a continuation of the themes of the ANT-XXIII/8 cruise. The main objective of the expedition was the investigation of potential effects of the climate change and ice shelf disintegration on ecosystems and biodiversity in the Antarctic region. It was part of the SCAR programme "Biodiversity and Evolution in the Antarctic: The response of life to environmental change" (Knust et al. 2012). 


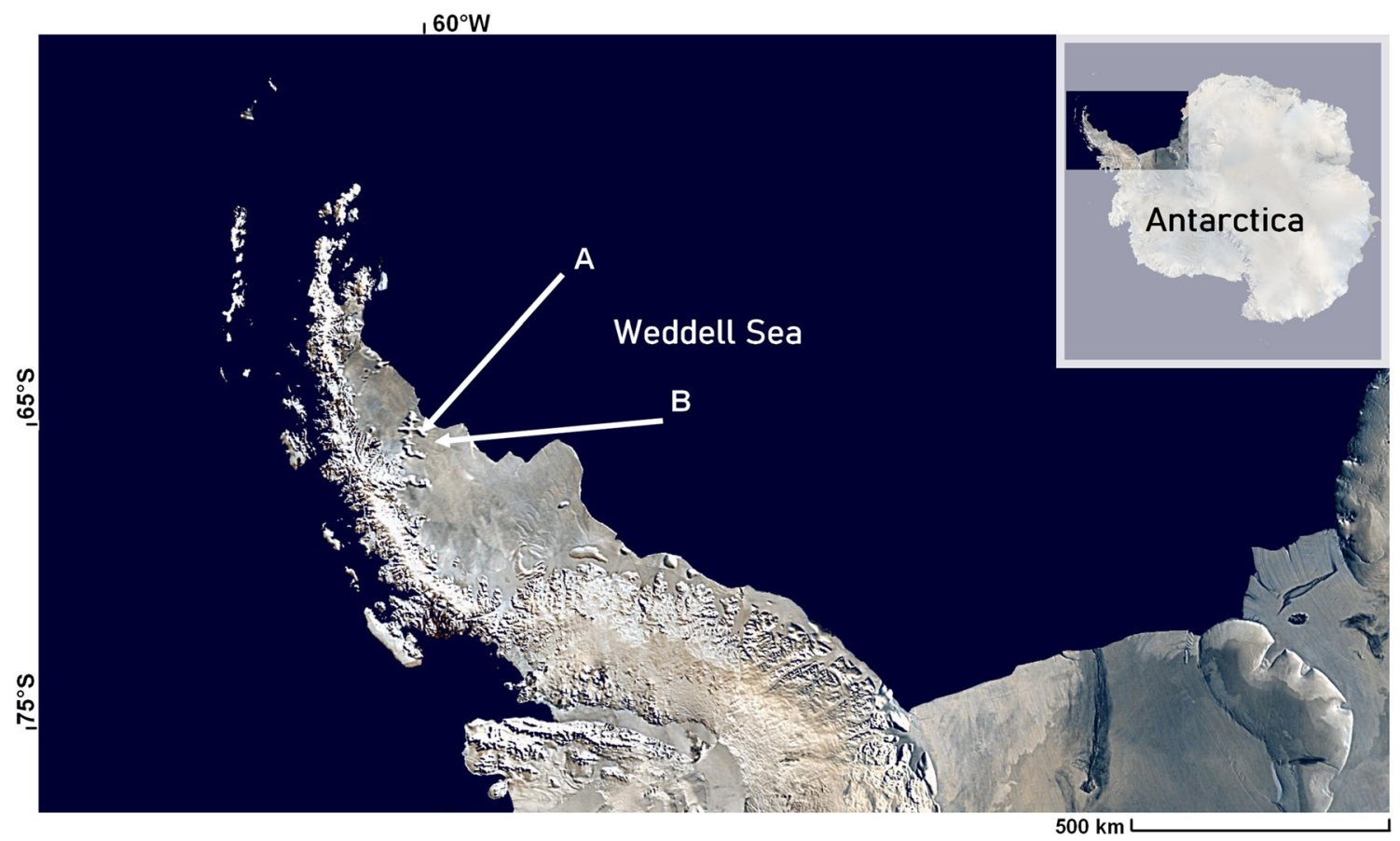

Fig. 1 Collection stations: a Finding locality of Abyssocladia antarctica sp. nov. at Larsen B; b Finding locality of Caulophacus (caulodiscus) leonieae sp. nov. at Larsen C. See Table 1 for sampling details (map from Dave Pape - own work, using Blue Marble data from http://visibleearth.nasa.gov/view_rec.php?id=2433)

\section{Material and methods}

The samples examined in this study were collected during two expeditions of the RV Polarstern: ANT-XXIII/8 in 2007 and ANT-XXVII/3 in 2011 (Fig. 1a, b). Both samples were taken in the western part of the Weddell Sea (Table 1). Sampling was undertaken by Agassiz Trawl (AGT) and Remotely Operated Vehicle (ROV) in depths between 215 and $305 \mathrm{~m}$.

The specimens were preserved in $96 \%$ ethanol rapidly after landing on deck. They were pre-sorted, labelled and deposited in the Porifera collection of the department of Marine Invertebrates I, Senckenberg Research Institute and Nature Museum, Frankfurt am Main, Germany.

Sponge spicules were obtained by boiling sponge fragments in nitric acid according to the modified method of the standard procedure (Boury-Esnault and Rützler 1997). Two small sections (each ca. $1 \mathrm{~cm}$ ) of the Abyssocladia (holotype) were cut off using a razor blade. Small sections of Caulophacus (holotype) were taken with tweezers from dermal, gastral, atrial surfaces and the stalk. All samples were washed in distilled water for $30 \mathrm{~min}$ to remove the remaining ethanol. The sponge fragments were transferred into individual test tubes which were filled with $65 \% \mathrm{HNO}_{3}$ (nitric acid) until the sections were completely covered. The tubes were mounted into a Block-Heater to heat the suspensions to $93{ }^{\circ} \mathrm{C}$ for $90 \mathrm{~min}$. Afterwards, the sponge fragments were completely dissolved. The resultant spicule suspensions were washed several times in distilled water. Disposable pipettes were used to mount drops of the spicule suspensions on SEM-stubs for scanning electron microscopy. After air drying, the stubs were sputter-coated with gold-palladium. Additionally, drops were mounted on glass slides for light microscopy, air-dried and then embedded in Euparal mounting medium (Roth). Furthermore, small sections of Abyssocladia were embedded in resin and then cut into thin sections.

Table 1 Sampling data of the examined specimens (extracted From Cruise Report ANT-XXIII/8, Gutt 2008 and Cruise Report ANT-XXVII/3 Knust et al. 2012)

\begin{tabular}{|c|c|c|c|c|c|c|c|c|c|}
\hline Expedition & Station & Area & Date & Time & Pos. (Lat.) & Pos. (Lon.) & Depth (m) & Gear & Action \\
\hline \multirow[t]{2}{*}{ ANT-XXIII/8 } & \multirow[t]{2}{*}{$702-9$} & Larsen B South & $1 / 12 / 2007$ & $19: 53$ & $65^{\circ} 57.85^{\prime} \mathrm{S}$ & $60^{\circ} 28.42^{\prime} \mathrm{W}$ & 221.4 & AGT & At bottom \\
\hline & & Larsen B South & $1 / 12 / 2007$ & $20: 19$ & $65^{\circ} 57.42^{\prime} \mathrm{S}$ & $60^{\circ} 28.12^{\prime} \mathrm{W}$ & 215 & AGT & Off bottom \\
\hline \multirow[t]{2}{*}{ ANT-XXVII/3 } & \multirow[t]{2}{*}{ PS77 241-1 } & Larsen C & $3 / 4 / 2011$ & $20: 24$ & $66^{\circ} 9.74^{\prime} \mathrm{S}$ & $60^{\circ} 28.28^{\prime} \mathrm{W}$ & 305 & ROV & On ground \\
\hline & & Larsen C & $3 / 5 / 2011$ & $0: 25$ & $66^{\circ} 9.80^{\prime} \mathrm{S}$ & $60^{\circ} 28.68^{\prime} \mathrm{W}$ & 296 & ROV & Hoisting \\
\hline
\end{tabular}


Every type of spicule of both sponges was measured using a calibrated ocular micrometer. Thirty spicules (if present) of each type were randomly selected for measuring, broken or malformed spicules were ignored. An example of how the measurements were taken is shown in Fig. 2.

SEM photographs were taken at the Senckenberg Research Institute Frankfurt am Main.

Types of spicules were identified using the Thesaurus of Sponge Morphology (Boury-Esnault and Rützler 1997), Systema Porifera (Hooper and van Soest 2002) and by comparison with corresponding scientific publications. We used the World Porifera Database as a guiding taxonomic reference (van Soest et al. 2020).

\section{Results}

\section{Systematics}

Phylum Porifera Grant, 1836

Class Demospongiae Sollas, 1885

Subclass Heteroscleromorpha Cárdenas, Pérez \& Boury-Esnault, 2012

Order Poecilosclerida Topsent, 1928

Family Cladorhizidae Dendy, 1922

Genus Abyssocladia Lévi, 1964

Type species

Abyssocladia bruuni Lévi, 1964 (by original designation)

\section{Diagnosis}

Cladorhizidae most often pedunculate, carrying a disciform or flabelliform body with a radial architecture; in other cases pinnate or branching. Microscleres are a combination of abyssochelae, cleistochelae, arcuate chelae and/or sigmancistras, but not placochelae (Hestetun et al. 2016 modified from Lopes et al. 2011).

\section{Abyssocladia antarctica sp. nov.}

http://zoobank.org/A5107B01-AAC7-48A0-86453F4413238A57

(Figs. 3 and 4; Tables 2 and 3)

Type material

Holotype. SMF11750(1) $\left(65^{\circ} 57.42^{\prime} \mathrm{S}, 60^{\circ} 28.12^{\prime} \mathrm{W}\right.$, Weddel Sea, Larsen B Shelf South, ca. 215-221 m depth, January 12, 2007). Deposited at Senckenberg Research Institute and Natural History Museum Frankfurt, Department of Marine Invertebrates I.

\section{Etymology}

The name Antarctica refers to the type locality. This is the first described species of the genus Abyssocladia in the High Antarctic region.

\section{Distribution}

Known, so far, only from its type locality in the region of the former Larsen B Ice Shelf in the Weddell Sea, Antarctica.

\section{Diagnosis}

Dichotomously branched Abyssocladia. Spicules include arcuate isochelae, abyssochelae and sigmancistras.

\section{Description}

Small, erect sponge body with branching, dichotomous habitus. Rounded peduncle, slightly expanding at the basal attachment. Branches generally arranged in one plane with only minor deviations. The sponge body, except for the peduncle, is covered with perpendicularly projecting filaments of around 1-2 mm length. The holotype has two basal attachments; it was collected as a single specimen and dissected later into eight fragments. The original height of the sponge could not be reconstructed, biggest measurable height of the main fragment (Fig. 3a) is $51 \mathrm{~mm}$. Branches are $1-2 \mathrm{~mm}$ in diameter, sometimes bearing umbrella-like buds. Its peduncle is $13 \mathrm{~mm}$ long and ca. $2 \mathrm{~mm}$ in diameter. The colour of the sponge in vivo as well as in ethanol is white (Fig. 3a, b).
Fig. 2 Measuring of different spicule types. a Abyssochela, (a1) Length, (a2) Width, (a3) Diameter of the shaft; b Oxea; c Strongyle; d Sigma, lengths and widths; e Pinule, (e1) Pinular ray, (e2) Tangential ray, (e3) Distal ray

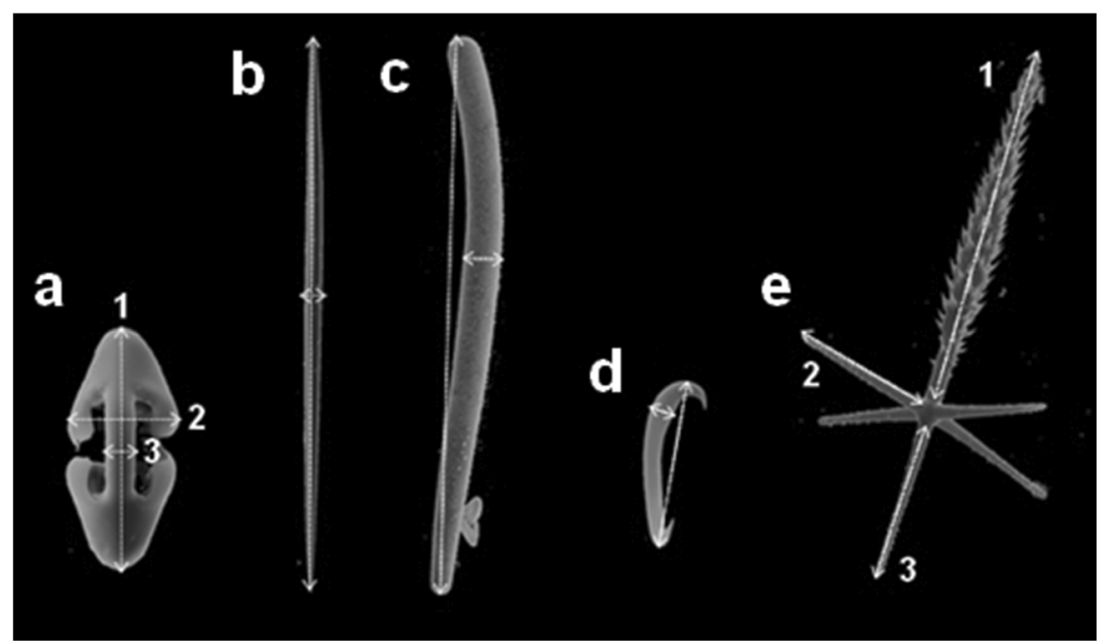


Fig. 3 Abyssocladia antarctica sp. nov. a, b Habitus holotype SMF 11750; c, d LM of the skeleton (c) Transversal section, scale $500 \mu \mathrm{m}$; d Longitudinal section, scale $200 \mu \mathrm{m}$; e-t SEM of the spicules. e-i Mycalostyles I, scales $100 \mu \mathrm{m}$; j Mycalostyle II, scale $30 \mu \mathrm{m}$; k Strongyle, scale $100 \mu \mathrm{m} ; \mathbf{l}-\mathbf{n}$ Arcuate Isochelae scales, $50 \mu \mathrm{m}$; o Sigmancistra scale, $10 \mu \mathrm{m} ; \mathbf{p}-\mathbf{t}$ Abyssochelae scales, $10 \mu \mathrm{m}$

Fig. 4 Arrows point exemplary towards spherical chambers filled with juvenile chelae of

Abyssocladia antarctica sp. nov. (Holotype). a LM of the skeleton longitudinal section, scale $200 \mu \mathrm{m}$; b Magnified picture of these chambers with visible juvenile chelae
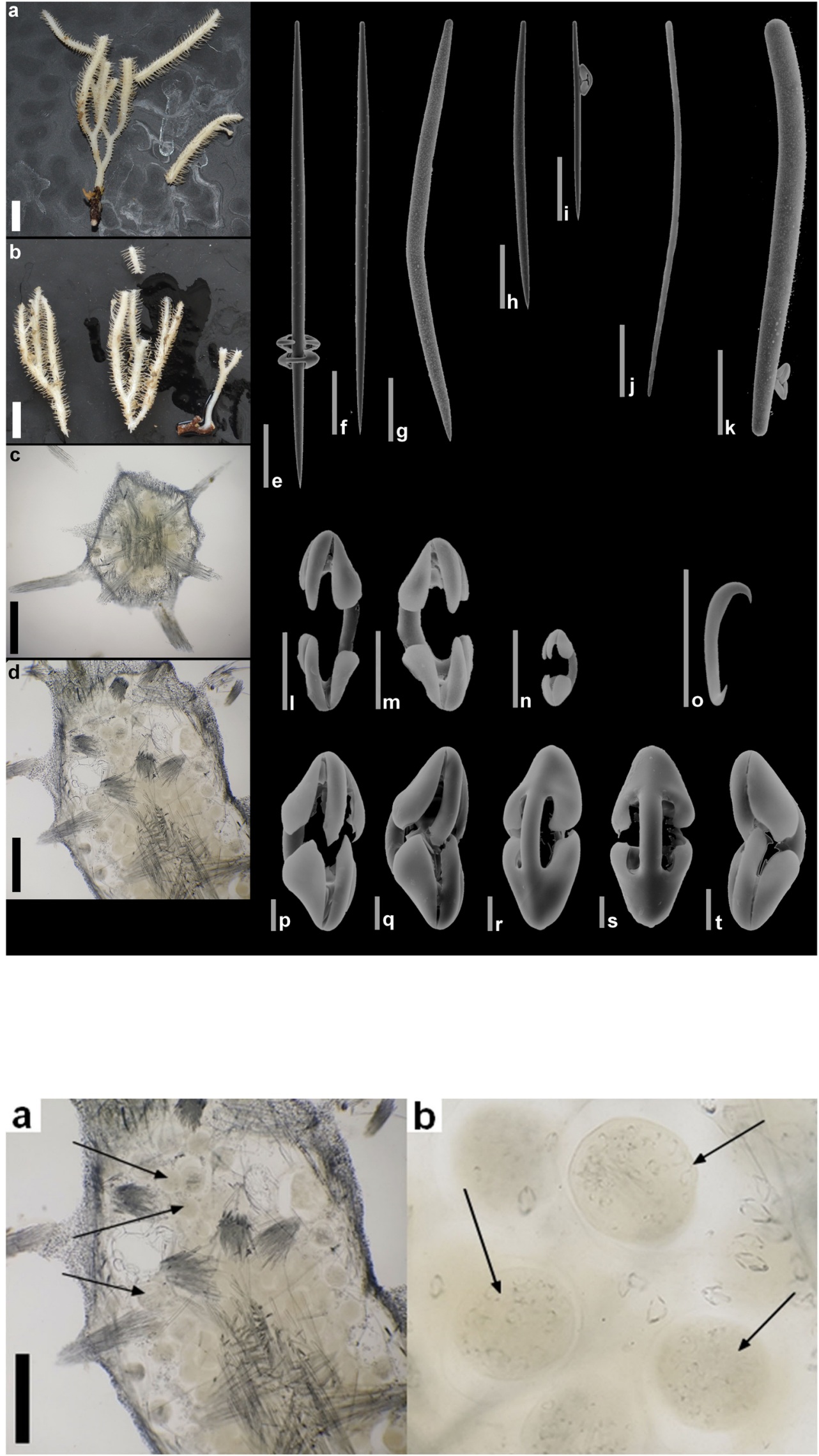
Table 2 Spicules dimensions of Abyssocladia antarctica sp. nov. All measurements are in micrometers: Avg. $=$ average size, $s d n=s t a n d a r d$ deviation, $\mathrm{L}=$ length, $\mathrm{W}=$ width, $\mathrm{D}=$ diameter of the shaft

\begin{tabular}{lllll}
\hline \multirow{2}{*}{ Abyssocladia antarctica sp. nov. } & \multicolumn{3}{l}{ SMF 11750 (Holotype) } \\
\cline { 2 - 5 } & Avg. & & sdn & min/max \\
\hline Mycalostyles I (large) & & & & \\
L & 792.3 & \pm & 128.9 & $(480-1000)$ \\
W & 22 & \pm & 3.5 & $(16-29)$ \\
Mycalostyles II (small) & & & & \\
L & 648.3 & \pm & 128.1 & $(360-860)$ \\
W & 6.9 & \pm & 2.3 & $(2-11)$ \\
Strongyle & & & & \\
L & 594.3 & \pm & 133.7 & $(270-890)$ \\
W & 25 & \pm & 6.2 & $(11-35)$ \\
Arcuate Isochelae & & & & \\
L & 64.4 & \pm & 10.8 & $(43-79)$ \\
W & 25.8 & \pm & 4.2 & $(17-31)$ \\
D & 6.5 & \pm & 1.2 & $(4-9)$ \\
Abyssochelae & & & & \\
L & 56.5 & \pm & 7.8 & $(41-76)$ \\
W & 23.7 & \pm & 3.3 & $(17-29)$ \\
D & 5.7 & \pm & 0.8 & $(4-7)$ \\
Sigmancistra LW & & & & \\
L & 10 & \pm & 0.6 & $(9-11)$ \\
D & 1 & \pm & 0 & \\
\hline
\end{tabular}

\section{Skeleton}

Filaments of the branches are formed of bundles of mycalostyles. The surface is covered by a dense layer of chelae. The soft tissue contains numerous spherical "chambers", containing chelae. Some of these chambers are filled only with developmental stages of chelae (Fig. $4 a, b$ ).

\section{Spicules}

(Fig. 3; Table 2)

Megascleres:

1. Mycalostyles I

Large Mycalostyles, generally straight and fusiform. One end blunt, the other tapers in the last third towards a pointed end (Fig. 3e-i).

$$
\text { Size 480-(792)-1000 × 16-(22)-29 } \mu \mathrm{m} \text {. }
$$

2. Mycalostyles II

Small Mycalostyles, generally thinner, not fusiform.

Generally straight, sometimes flexuous appearance. Less abundant than mycalostyles I (Fig. 3j).

Size 360-(648)-860 × 2-(7)-11 $\mu \mathrm{m}$.

3. Strongyles

Slight to moderately bend, sometimes distinctively bend.

Not very abundant (Fig. $3 k$ ).

Size 270-(594)-890 × 11-(25)-35 $\mu \mathrm{m}$.

Microscleres:

4. Arcuate isochelae

Shaft moderately curved, alae roughly ovoid. Very abundant (Fig. 31-n).

Table 3 Comparison of spicules composition in morphologically similar species of Abyssocladia (A. diegoramirezensis, A. leverhulmei) and of species with similar abyssochelae (A. corniculiphora, A. dominalba, A. lakwolli). X, type of spicule is present in that species

\begin{tabular}{|c|c|c|c|c|c|c|}
\hline & $\begin{array}{l}\text { Abyssocladia antarctica } \\
\text { sp. nov. } \\
\text { SMF } 11750 \text { (Holotype) }\end{array}$ & $\begin{array}{l}\text { A. corniculiphora } \\
\text { (Hestetun et al. } \\
2017 \text { ) }\end{array}$ & $\begin{array}{l}\text { A. diegoramirezensis } \\
\text { (Lopes et al. 2012) }\end{array}$ & $\begin{array}{l}\text { A. dominalba } \\
\text { (Vacelet 2006) }\end{array}$ & $\begin{array}{l}\text { A. lakwolli } \\
\text { (Hestetun et al. } \\
\text { 2017) }\end{array}$ & $\begin{array}{l}\text { A. leverhulmei } \\
\text { (Goodwin et al. } \\
\text { 2017) }\end{array}$ \\
\hline Styles / Mycalostyles I & $\mathrm{X}$ & $\mathrm{X}$ & $X$ & $\mathrm{X}$ & $X$ & $\mathrm{X}$ \\
\hline Styles / Mycalostyles II & $X$ & $\mathrm{X}$ & $X$ & & $X$ & \\
\hline Strongyles & $\mathrm{X}$ & & $\mathrm{X}$ & & & $\mathrm{X}$ \\
\hline Arcuate Isochelae & $\mathrm{X}$ & & $X$ & $\mathrm{X}$ & $X$ & $\mathrm{X}$ \\
\hline Abyssochelae & $\mathrm{X}$ & & $\mathrm{X}$ & $\mathrm{X}$ & & $\mathrm{X}$ \\
\hline Sigmancistra 1 & $\mathrm{X}$ & $X$ & $\mathrm{X}$ & $\mathrm{X}$ & $X$ & $\mathrm{X}$ \\
\hline Sigmancistra 2 & & & & $\mathrm{X}$ & & \\
\hline Anisochelae & & & & $\mathrm{X}$ & & \\
\hline Cleistochelae & & $X$ & & & $X$ & \\
\hline Sigmas & & & $X$ & & & \\
\hline Substrongyles & & & & & $X$ & \\
\hline Anchorate Isochelae 1 & & & & & $\mathrm{X}$ & \\
\hline Anchorate isochelae 2 & & & & & $X$ & \\
\hline
\end{tabular}


Size 43-(64)-79 × 17-(26)-31 $\mu \mathrm{m}$, shaft 4-(7)-9 $\mu \mathrm{m}$ in diameter.

5. Abyssochelae

Strongly curved shaft. Front alae long and considerably slanted at top, interfingering with and nearly touching opposite ala. Very abundant (Fig. 3p-t).

Size 41-(57)-76 × 17-(24)-29 $\mu \mathrm{m}$, shaft 4-(6)-7 $\mu \mathrm{m}$ in diameter.

6. Sigmancistra

Shaft slightly twisted. Flattened at one end. Very abundant (Fig. 3o).

Size 9-(10)-11 $\mu \mathrm{m}$ in length, shaft $1 \mu \mathrm{m}$ in diameter.

\section{Remarks}

As of August 2020, 37 valid species of the genus Abyssocladia are known (van Soest et al. 2020). Only two species have a similar dichotomic branched shape:

A. diegoramirezensis Lopes, Bravo \& Hajdu, 2012 and A. leverhulmei Goodwin, Berman, Downey \& Hendry, 2017 with $A$. leverhulmei being the only species of Abyssocladia that shows a clear morphological resemblance to $A$. antarctica sp. nov. (Fig. 5). Several species are similar, but all of them grow as a single stem and are not branched. Consequently, 35 species could be excluded from extensive comparison in terms of their morphological appearance.

Furthermore, Abyssocladia antarctica sp. nov. possesses a unique type of abyssochelae that bears only a superficial resemblance to those of other species. Only three species with similar abyssochelae exist: A. dominalba Vacelet, 2006, A. lakwolli Vacelet \& Kelly, 2014 and A. corniculiphora Hestetun, Rapp \& Xavier, 2017. There is no species that bears a morphological resemblance and similar abyssochelae to A. antarctica sp. nov.. A detailed comparison of these five species showed that $A$. antarctica sp. nov. is a so far undescribed species with a unique spicule composition (Table 3).
Class Hexactinellida Schmidt, 1870

Subclass Hexasterophora Schulze, 1886

Order Lyssacinosida Zittel, 1877

Family Rosselidae Schulze, 1885

Genus Caulophacus Schulze, 1886

Subgenus Caulodiscus Ijima, 1927

Type species

Caulophacus latus Schulze, 1886 (by subsequent designation; Koltun, 1967).

Diagnosis.

Microscleres with various terminations: discoidal, onychoidal and oxyoidal (Tabachnick and Reiswig 2002).

Caulophacus (caulodiscus) leonieae sp. nov.

http://zoobank.org/FDC2E253-8C51-4A92-9769F47A4B13A342

(Figs. 6, 7 and 8; Table 4)

Type material

Holotype. SMF12217 (669.74‘S, 60²8.28‘W, Weddell Sea, Larsen C Shelf, ca. 296-305 m depth, March 04, 2011). Stored at Senckenberg Research Institute and Natural History Museum Frankfurt, department of Marine Invertebrates I.

\section{Etymology}

Named after the first author's firstborn daughter, Leonie, who was born shortly after completing this study.

\section{Distribution}

Only known from its type locality in the region of the Larsen C Ice Shelf in the Weddell Sea, Antarctica.

\section{Diagnosis}

Body fungiform. Spicules diactins, hexactins, pinular pentactins, pinular hexactins, discohexactins, onychohexaster and microonychohexactins.

\section{Description}

Fungiform Caulophacus with two stalks, small and erect. The discoidal body part is $49 \mathrm{~mm}$ in diameter and $13 \mathrm{~mm}$ in thickness. The surface is covered with small dimples, diverging in sizes. One stalk is $33 \mathrm{~mm}$ long and $4 \mathrm{~mm}$ in diameter,
Fig. 5 Morphological comparison of a Abyssocladia leverhulmei (Holotype (Goodwin et al. 2017)); b Abyssocladia diegoramirezensis (Holotype, (Lopes et al. 2012)) and c Abyssocladia antarctica sp. nov. (scales: $\mathbf{a}-\mathbf{c}=10 \mathrm{~mm}$ )
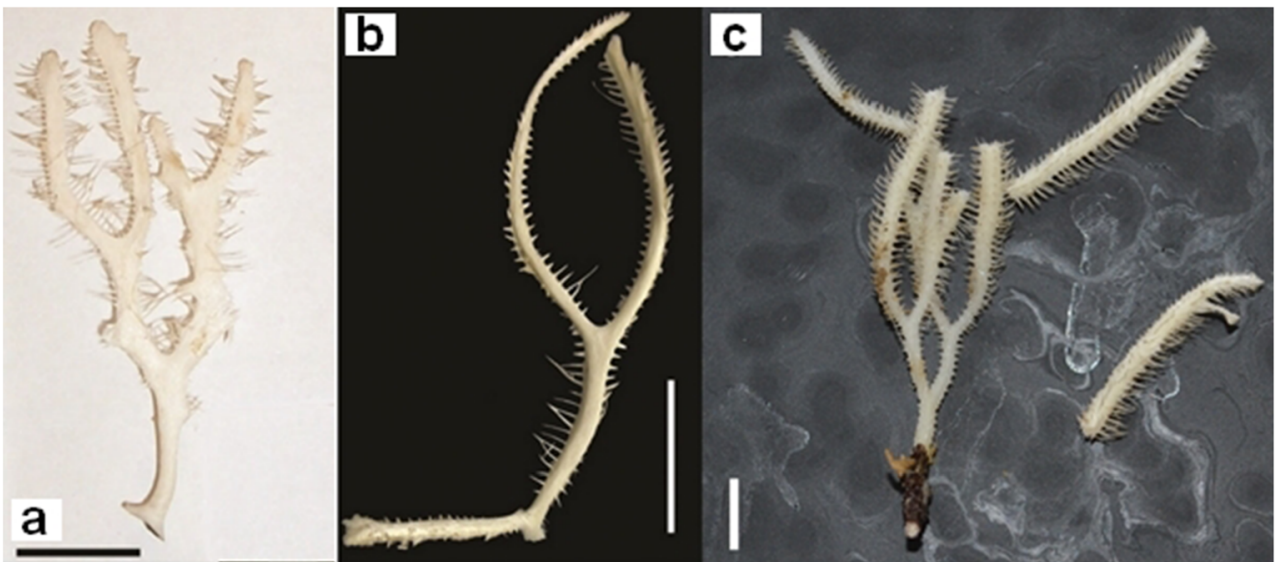

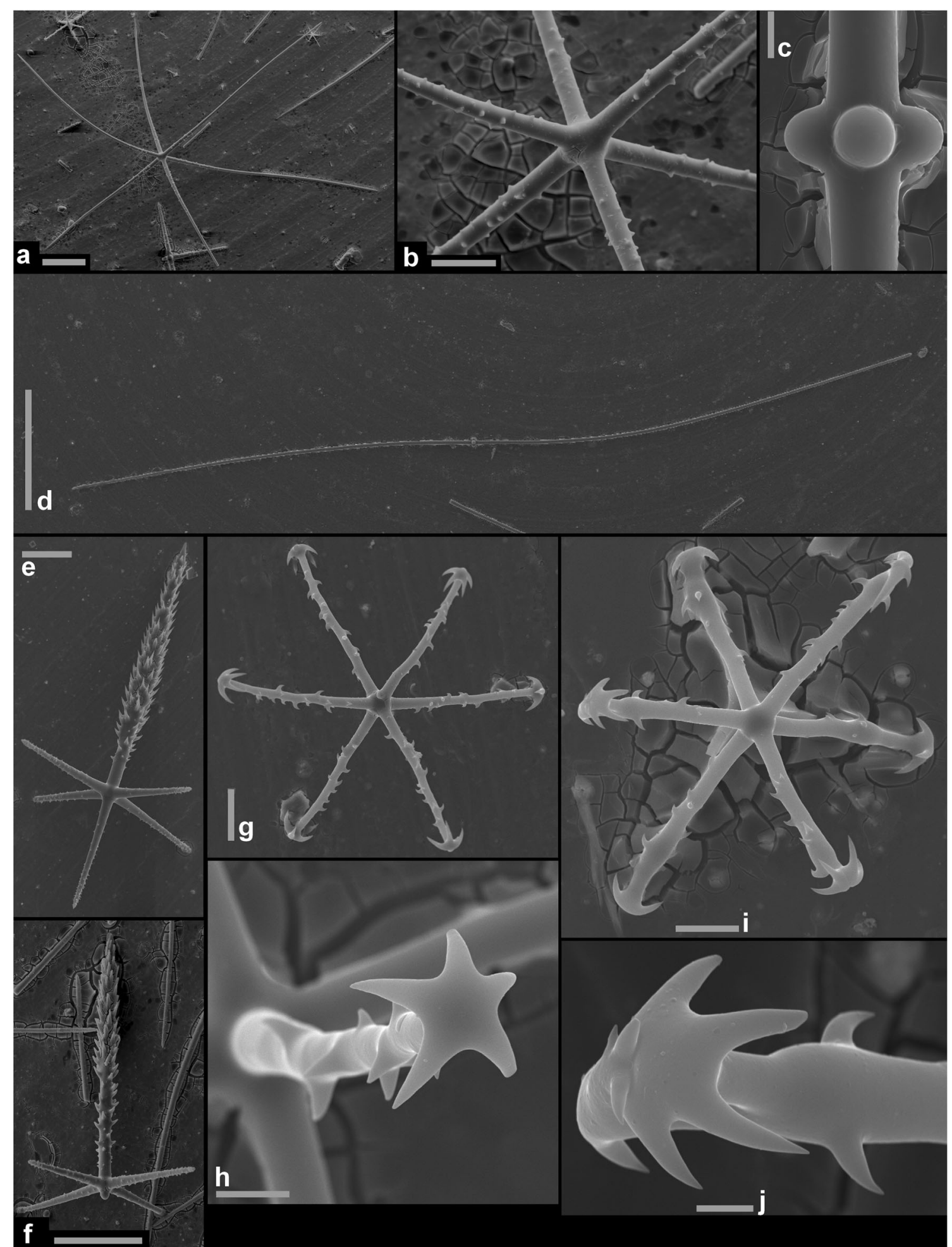

Fig. 6 Caulophacus leonieae sp. nov. a, b Dermal hexactin scale: a $100 \mu \mathrm{m}$; b $30 \mu \mathrm{m}$; c, d Gastral diactine scale: c $5 \mu \mathrm{m}$; d $200 \mu \mathrm{m}$; e Gastral pinular hexactin scale: $50 \mu \mathrm{m}$; f Dermal pinular pentactin scale:

the other is $40 \mathrm{~mm}$ long and $5 \mathrm{~mm}$ in diameter. Both are ruptured at their bases, revealing that the stalks are hollow. Basal attachments are not preserved. The biggest measurable height is $48 \mathrm{~mm}$. The body is flexuous and soft. The colour of
$100 \mu \mathrm{m} ; \mathbf{g}, \mathbf{h}$ Discohexactin scale: $\mathbf{g} 20 \mu \mathrm{m} ; \mathbf{h} 5 \mu \mathrm{m} ; \mathbf{i}, \mathbf{j}$ Microonychohexactin scale: i $10 \mu \mathrm{m} ; \mathbf{j} 2 \mu \mathrm{m}$

the specimen upon collection and in ethanol is white to yellowish (Fig. 7a, b).

\section{Spicules}

(Figs. 6 and 7; Table 4) 
Fig. 7 Caulophacus leonieae sp. nov. a, b Holotype scale: $10 \mathrm{~mm}$; c Microonychohexactin scale: $10 \mu \mathrm{m} ; \mathbf{d} \mathrm{LM}$ of onychohexaster

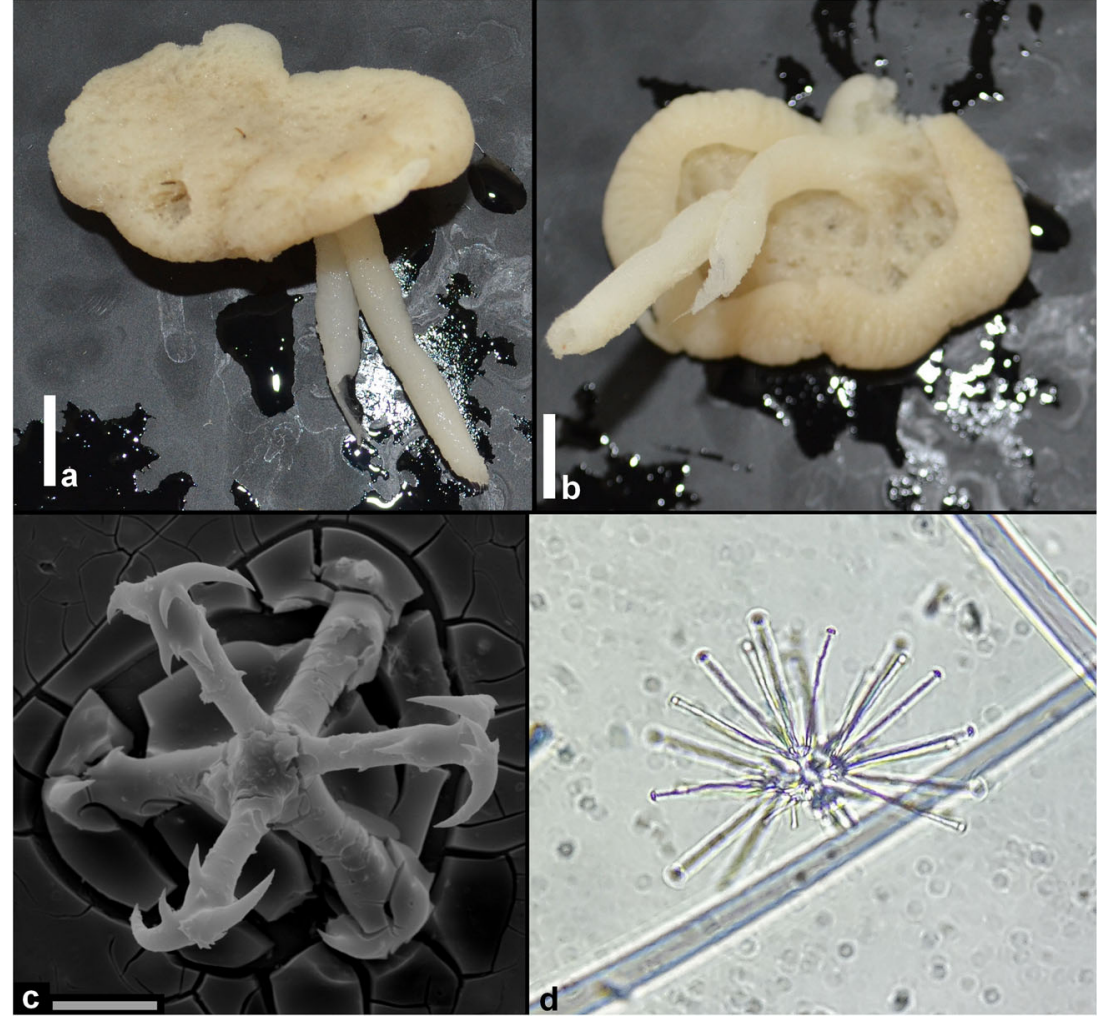

Dermal spicules are diactins, hexactins, pinular pentactins, pinular hexactins, discohexactins, onychohexaster and microonychohexactins. Hexactins can vary vastly from small to very large. Pinular rays are mostly conically shaped. Only two complete onychohexaster and two broken ones were found in the preparation. Gastralia are diactins, hexactins, rarely pinular pentactins, pinular hexactins, discohexactins and very few mikroonychohexactins. Pinular pentactins and hexactins differ from dermal ones. They are considerably smaller with spindle-like pinular rays. Choanosomalia are diactins, hexactins, rarely pinular pentactins or pinular hexactins, discohexactins and microonychohexactins. The stalk contains predominantly diactins and pinular pentactins. Rarely hexactins and no pinular hexactins or microscleres.

Two possible pentactins were found in the preparation. But it could not be excluded that these pentactins are in fact hexactins with a very smooth point of rupture. Large spicules were mostly broken and could not be measured properly in the standard quantity. Therefore, Diactins and Hexactins are not included in Table 4.

Megascleres:

1. Hexactin

Usually rough to spiny towards the base. In some cases, a
Fig. 8 Morphological comparison of a Holotype of Caulophacus (caulodiscus) leonieae sp. nov. (SMF12217); b Holotype of Caulophacus (caulodiscus) brandtae (SMF51) scale: a, b $10 \mathrm{~mm}$

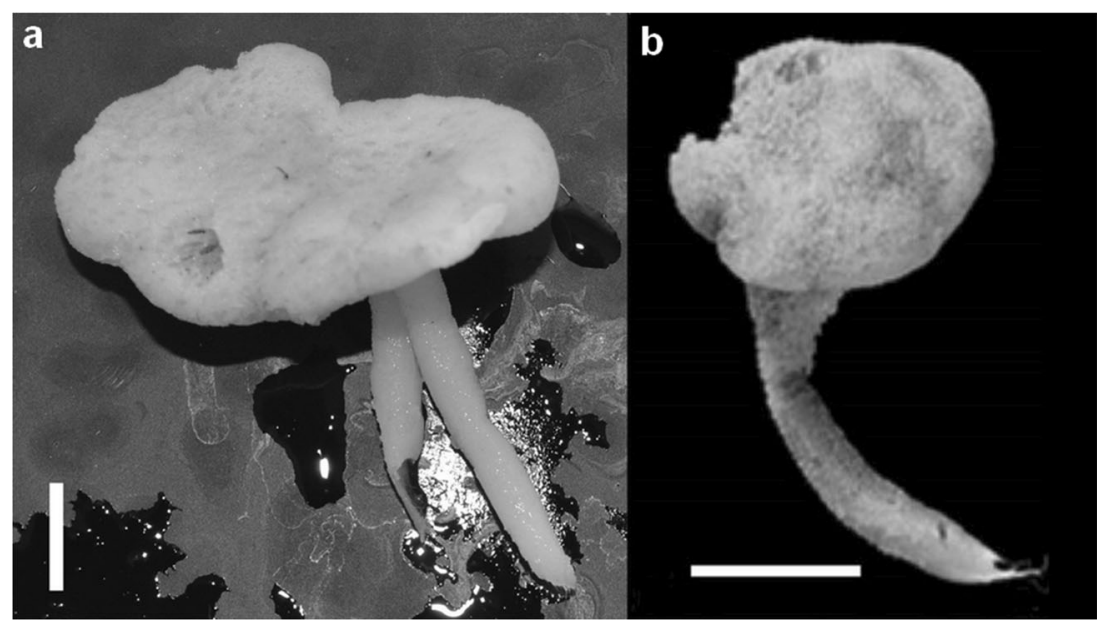


Table 4 Spicules dimensions of Caulophacus leonieae sp. nov.: All measures are in micrometers: $N$, number of specimens; Avg., average size; $s d n$, standard deviation; $L$, length; $D$, diameter of spicule

\begin{tabular}{|c|c|c|c|c|c|}
\hline \multirow[t]{2}{*}{ Caulophacus leonieae sp. nov. } & \multicolumn{5}{|c|}{ P77 ROV (Holotype) } \\
\hline & Avg. & & $\operatorname{sdn}$ & $\min / \max$ & $\mathrm{N}$ \\
\hline \multicolumn{6}{|c|}{ Dermal pinular hexactin, pinular ray } \\
\hline $\mathrm{L}$ & 309 & \pm & 37 & $(200-370)$ & 20 \\
\hline \multicolumn{6}{|c|}{ Dermal pinular hexactin, tangential ray } \\
\hline $\mathrm{L}$ & 112 & \pm & 13 & $(73-130)$ & 20 \\
\hline \multicolumn{6}{|l|}{ Dermal pinular hexactin, distal ray } \\
\hline $\mathrm{L}$ & 111 & \pm & 9 & $(100-130)$ & 20 \\
\hline \multicolumn{6}{|c|}{ Gastral pinular hexactin, pinular ray } \\
\hline $\mathrm{L}$ & 246 & \pm & 27 & $(200-290)$ & 21 \\
\hline \multicolumn{6}{|c|}{ Gastral pinular hexactin, tangential ray } \\
\hline $\mathrm{L}$ & 102 & \pm & 14 & $(80-130)$ & 21 \\
\hline \multicolumn{6}{|l|}{ Gastral pinular hexactin, distal ray } \\
\hline $\mathrm{L}$ & 104 & \pm & 9 & $(80-120)$ & 21 \\
\hline \multicolumn{6}{|l|}{ Discohexactin } \\
\hline $\mathrm{D}$ & 119 & \pm & 18 & $(83-165)$ & 30 \\
\hline \multicolumn{6}{|l|}{ Microonychohexactin } \\
\hline $\mathrm{D}$ & 47 & \pm & 9 & $(31-63)$ & 14 \\
\hline \multicolumn{6}{|l|}{ Onychohexaster } \\
\hline $\mathrm{D}$ & 46 & \pm & 11 & $(35-57)$ & 2 \\
\hline
\end{tabular}

single ray is roughened towards the outer end, as well whereas the five other rays have smooth ends. Hexactins vary vastly in size. Large rays are flexuous, small hexactins appear rather stiff. Preparation contained only few small hexactins in contrast to the big hexactins. Therefore, it is assumed that the small hexactins are juvenile forms (Fig. 6a, b).

Size: Proximal/distal rays, length: $350-450 \mu \mathrm{m}$, diameter (max) $10.5 \mu \mathrm{m}$; Radial rays: 450-550 $\mu \mathrm{m}$, diameter: $10 \mu \mathrm{m}$

2. Diactin

Diactins have four small bulges in the middle which are interpreted as atrophied rays of hexactins. The diactine ends are rounded or pointy and slightly rough (Fig. 6c, d). Size length: $800-2000 \mu \mathrm{m}$, diameter max near central axial cross: $15 \mu \mathrm{m}$

3. Pinular dermal hexactin

Hexactins with a conically shaped or spindle-like, rarely ovoid, pinular distal ray. Tangential rays are rough and taper towards a conically pointed outer end. in most pinules roughness increases towards the terminal end. Proximal ray identical to the tangential rays in terms of diameter and surface but may vary slightly in length (Fig. 6e).

Size Pinular ray 200-(309)-370 $\mu \mathrm{m}$, Tangential ray

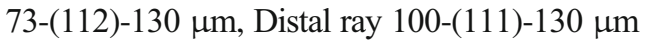

4. Pinular dermal pentactin

Pentactin with a pinular ray which is usually conically formed or spindle-like, rarely ovoid. Tangential rays are rough and taper towards conically pointed outer ends. Roughness usually increases towards the terminal ends. Small bulge on opposite site of the pinular ray is interpreted as an atrophied proximal ray (Fig. 6f). Size range of pentactine pinule is the same as that of hexactin pinule, except for the atrophied ray.

Size: Distal (pinular) ray: $130-160 \mu \mathrm{m}$, diameter $(\max )$ $20 \mu \mathrm{m}$, Proximal ray: 125-140 $\mu \mathrm{m}$, diameter $(\max ) 9 \mu \mathrm{m}$. Radial rays: $50-55 \mu \mathrm{m}$, diameter (max): $8 \mu \mathrm{m}$

5. Discohexactin

Hexactin spicules with discoidal ends. Bearing several hook- or claw-like processes, very abundant (Fig. 6g, h). Size 83-(119)-165 $\mu \mathrm{m}$.

\section{Microscleres:}

6. Onychohexaster

Spherical hexasters with numerous secondary rays on each principle. Very rare, only two complete ones were found in light microscopy (Fig. 7d).

Size 35-(46)-57 $\mu \mathrm{m}$.

7. Microonychohexactin

Comparably small hexactins with onychoidal ends, moderately abundant. Terminal ends have a more or less anchorate shape, bearing several claw-like processes. These processes also appear alongside the rays towards the terminal ends. Rays have usually slight but distinctive 
swellings shortly before the terminal ends (Figs. 6i, $\mathrm{j}$ and 7c).

Size 31-(47)-63 $\mu \mathrm{m}$.

\section{Remarks}

This new species equates in almost every characteristic to the already described species Caulophacus (caulodiscus) brandtae Janussen, Tabachnick and Tendal, 2004. Both species were discovered in the Weddell Sea and have a very similar body appearance (Fig. 8). They share an almost identical spicule-composition, matching in all but one type of spicule. A close look at the individual spicules of both species shows that they even match in terms of texture, terminal endings or in variations of their pinular rays. One additional feature in Caulophacus (caulodiscus) leonieae sp. nov., in contrast to $C$. $(C$.) brandtae, is that the new species possesses microonychohexactins, a previously unknown type of spicules in this genus here described and documented for the first time (Figs. 6i, j and 7c). Since Caulophacus (caulodiscus) leonieae sp. nov. does resemble $C$. $(C$.) brandtae with the difference of this additional new type of microscleres, it is here assigned to the same subgenus Caulodiscus.

\section{Discussion}

The two new species Abyssocladia antarctica sp. nov. and Caulophacus (caulodiscus) leonieae sp. nov. belong to otherwise well-known deep-sea sponge genera that usually occur in bathyal and abyssal depths. Representatives of the genus Abyssocladia are known from depths of ca. $1000 \mathrm{~m}$ (Goodwin et al. 2017) down to $6127 \mathrm{~m}$ (Vacelet 2006). The very similar species to Caulophacus (caulodiscus) leonieae sp. nov., C. (C.) brandtae, was discovered between 1153 and $1223 \mathrm{~m}$ depth (Janussen et al. 2004). Compared to these abyssal depths, the occurrence at ca. $300 \mathrm{~m}(C$. (C.) leonieae sp. nov.) and ca. $220 \mathrm{~m}$ (Abyssocladia antarctica sp. nov.) is truly exceptional and raises the question, why these deep-sea taxa appear in such shallow depths. A possible answer can be found by taking a close look at the rather exceptional circumstances of the sponge habitats: both specimens were discovered in areas that have been permanently covered by ice for at least several hundreds of years (Scambos et al. 2000). The recent collapse of the Larsen Ice Shelf provided the first opportunity to investigate the changes in formerly sub-shelf ecosystems shortly after its ice-shelf loss. Those and other break-up events can be directly linked to global warming, in this case to an increase of the mean temperature in the region of the Antarctic Peninsula. Weather stations at the Antarctic Peninsula had indicated a rising of $2.5^{\circ} \mathrm{C}$ of the annual mean air temperature between 1950 and 2000 (Scambos et al. 2000). The ANTXXIII/8 expedition of the RV Polarstern in 2007 to the formerly shelf-covered areas found a benthic ecosystem that contained several typical deep-sea taxa, including representatives of echinoids, hyocrinidae, gastropods and sponges, that are usually known from depth $>1000 \mathrm{~m}$, which were all living on the shelf in much shallower depths (Gutt et al. 2011). This discovery led to the hypothesis that sub-shelf areas provide similar conditions as deep-sea environments. Deep-sea benthic communities depend on organic matter from euphotic zones with primary production. Icecovered shelf areas are assumed to receive less nutrients input from the water surface and its benthic animals thus to rely largely on input by currents, similar to deep-sea environments. Gutt et al. (2011) proposed that the decomposition of organic matter during transit from euphotic zones to the deep sea may be similar as in transition from open water to sub-shelf areas. In conclusion, a deep-sea like environment seems to allow deep-sea sponges to thrive even in such shallow depths. An analogue example may be seen in the occurrence of the deep-sea carnivore demosponge, Lycopodina hypogea (Vacelet and Boury-Esnault 1996) at shallow depths in a Mediterranean submarine cave, where the supply of suspended nutrients in the sea water is low compared to the surrounding environment outside the cave. Another finding of a carnivorous sponge, Lycopodina vaceleti (van Soest and Baker 2011), was reported from shallow water of the Antarctic McMurdo Sound (van Soest and Baker 2011). Whereas it is known that Asbestopluma and Lycopodina may occur at shallow depths in some rare cases, this is the first report of the genus Abyssocladia outside abyssal and bathyal environments.

The observations of the ANTXXIII/8 cruise indicate that this ecosystem is in a dynamic process of rapid change. The disintegration of Larsen A (1995) and Larsen B (2002) was only 7 years apart. Nonetheless, ecosystem surveys completed on RV Polarstern showed a clear difference in species composition and richness within both areas. These snapshots of the shelf ecosystems revealed that both communities are rapidly changing: sponges are thriving and very abundant due to the increased nutrient input and many new juvenile sponges were observed by the RV Polarstern expedition in 2011 (Fillinger et al. 2013). In fact, these sponge species of the genera Rossella and Anoxycalyx (joubini) had the advantage to already be at the right place when the conditions changed. It is assumed that these newly ice-free shelf areas are in the process of transition into a typical Weddell Sea shelf community (Gutt et al. 2011), subsequently replacing deep-sea sponge species with characteristic Antarctic shelf fauna.

It is assumed that the newly described species Abyssocladia antarctica sp. nov. and Caulophacus (caulodiscus) leonieae sp. nov. already existed in the subshelf benthic community before the disintegration of the ice cover took place. This suggests that there may be 
undiscovered ecosystems harbouring undescribed deep-sea species everywhere in Antarctic sub-ice-shelf areas. The results of other studies (Gutt et al. 2011; Fillinger et al. 2013; Linse et al. 2020) also suggest that formerly sub-shelf communities change dramatically once they are exposed to new trophic conditions, effectively leading to a potential loss of aboriginal species. The rise of the global mean temperature has instigated processes that lead to the ongoing disintegration of these ice shelves including the loss of specialized, yet hitherto unknown species which may never be discovered.

Acknowledgements We acknowledge Julian Gutt (AWI Bremerhaven) for the initiation of two expeditions to the former Larsen ice-shelves and all the other colleagues dedicated to the research on these precious Antarctic environments. Thanks to Camino Eck (cand. Biol, Frankfurt Univ.) for valuable discussions, to Saskia Dimter, Marie-Louise Tritz and Claudia Franz of the section Marine Evertebrates I for their technical assistance. We thank Michelle Klautau and one other anonymous reviewer for comments that improved an earlier version of this paper. We thank Julia D. Sigwart for a linguistic check of and further valuable input to this manuscript. Furthermore, we thank the captain and crew of RV POLARSTERN for very good collaboration. DJ acknowledges Deutsche Forschungsgemeinschaft for financial support to her sponge research at the former Larsen Ice-shelves (JA-1063/17-1).

Funding Open Access funding enabled and organized by Projekt DEAL.

\section{Compliance with ethical standards}

Conflict of interest The authors declare that they have no conflict of interest.

Ethical approval All applicable international, national, and/or institutional guidelines for the care and use of animals were followed by the authors.

Sampling and field studies All necessary permits for sampling and observational field studies have been obtained by the authors from the competent authorities and are mentioned in the "Acknowledgements", if applicable.

Data availability All data generated or analysed during this study are included in this published article. Sponge specimens are electronically catalogued in SESAM and stored at Senckenberg Research Institute and Nature Museum, Senckenberganlage 25, D-60325 Frankfurt am Main, Section Marine Evertebrates I. For requests please contact Dorte Janussen (dorte.janussen@senckenberg.de).

Author contribution The taxonomic research was done by DB and DJ in collaboration, text and figures were made by DB with scientific input by DJ and the samples were collected by DJ.

Open Access This article is licensed under a Creative Commons Attribution 4.0 International License, which permits use, sharing, adaptation, distribution and reproduction in any medium or format, as long as you give appropriate credit to the original author(s) and the source, provide a link to the Creative Commons licence, and indicate if changes were made. The images or other third party material in this article are included in the article's Creative Commons licence, unless indicated otherwise in a credit line to the material. If material is not included in the article's Creative Commons licence and your intended use is not permitted by statutory regulation or exceeds the permitted use, you will need to obtain permission directly from the copyright holder. To view a copy of this licence, visit http://creativecommons.org/licenses/by/4.0/.

\section{References}

Boury-Esnault N, Rützler K (1997) Thesaurus of sponge morphology. Smithsonian Contributions to Zoology:1-55

Cárdenas, P. Pérez, T.; Boury-Esnault, N. (2012). Sponge systematics facing new challenges. In: Becerro MA, Uriz MJ, Maldonado M, Turon X (eds) Advances in sponge science: phylogeny, systematics, Ecology. Advances in Marine Biology 61:79-209

Dendy A (1922) Report on the Sigmatotetraxonida collected by H.M.S. 'Sealark' in the Indian Ocean. In: Reports of the Percy Sladen Trust Expedition to the Indian Ocean in 1905, Vol. 7. Transactions of the Linnean Society of London 18(1);1-164:1-18

Fillinger L, Janussen D, Lundälv T, Richter C (2013) Rapid glass sponge expansion after climate-induced Antarctic ice shelf collapse. Curr Biol 23:1330-1334

Goodwin CE, Berman J, Downey RV, Hendry KR (2017) Carnivorous sponges (Porifera : Demospongiae : Poecilosclerida : Cladorhizidae) from the Drake Passage (Southern Ocean) with a description of eight new species and a review of the family Cladorhizidae in the Southern Ocean. Invertebr Syst 31:37-64

Grant RE (1836) Animal Kingdom. Pp. 107-118. In: Todd, R.B. (Ed.), The Cyclopaedia of Anatomy and Physiology. Volume 1. (Sherwood,Gilbert, and Piper: London): 1-813

Gutt J (2008) Reports on polar and marine research: the expedition ANTXXIII/8 of the research vessel "Polarstern" to the Antarctic in 2006/2007

Gutt J, Barratt I, Domack E, d'Udekem d'Acoz C, Dimmler W, Grémare A, Heilmayer O, Isla E, Janussen D, Jorgensen E, Kock K-H, Sophia Lehnert L, López-Gonzáles P, Langner S, Linse K, Eugenia Manjón-Cabeza M, Meißner M, Montiel A, Raes M, Robert H, Rose A, Sañé Schepisi E, Saucède T, Scheidat M, Schenke H-W, Seiler J, Smith C (2011) Biodiversity change after climate-induced ice-shelf collapse in the Antarctic. Deep-Sea Res II Top Stud Oceanogr 58:74-83

Hestetun JT, Vacelet J, Boury-Esnault N, Borchiellini C, Kelly M, Ríos P, Cristobo J, Rapp HT (2016) The systematics of carnivorous sponges. Mol Phylogenet Evol 94:327-345

Hestetun JT, Rapp HT, Xavier J (2017) Carnivorous sponges (Porifera, Cladorhizidae) from the Southwest Indian Ocean Ridge seamounts. Deep-Sea Res II Top Stud Oceanogr 137:166-189

Hooper JNA, van Soest RWM (2002) Systema Porifera. A guide to the classification of sponges. In: Systema Porifera. Springer, Boston, pp $1-7$

Ijima I (1927) The Hexactinellida of the Siboga expedition. Pp. i-viii, 1383, pls I-XXVI. In: Weber, M. (Ed.) Siboga-Expeditie. Uitkomsten op zoologisch, botanisch, oceanographisch en geologisch gebied verzameld in Nederlandsch Oost-lndië 1899-1900 aan boord H.M. 'Siboga' onder commando van Luitenant ter zee 1e kl. G.F. Tydemann. 106 (Monographie VI) (E.J. Brill, Leiden)

Janussen D, Tabachnick KR, Tendal OS (2004) Deep-sea Hexactinellida (Porifera) of the Weddell Sea. Deep-Sea Res II Top Stud Oceanogr 51:1857-1882

Knust R, Gerdes D, Mintenbeck, K. (2012) Reports on polar and marine research: the expedition of the research vessel "Polarstern" to the Antarctic in 2011 (ANT-XXVII/3) (CAMBIO)

Lévi C (1964) Spongiaires des zones bathyale, abyssale et hadale. Galathea report. Scientific results of the Danish Deep-Sea expedition round the world. 1950-52(7):63-112

Linse K, Sigwart JD, Chen C, Krylova EA (2020) Ecophysiology and ecological limits of symbiotrophic vesicomyid bivalves (Pliocardiinae) in the Southern Ocean. Polar Biol 43:1423-1437 
Lopes DA, Bravo A, Hajdu E (2012) New carnivorous sponges (Cladorhizidae : Poecilosclerida : Demospongiae) from off Diego Ramírez Archipelago (South Chile), with comments on taxonomy and biogeography of the family. Invertebr Syst 25:407-443

Scambos TA, Hulbe C, Fahnestock M, Bohlander J (2000) The link between climate warming and break-up of ice shelves in the Antarctic peninsula. J Glaciol 46:516-530

Schmidt O (1870) Grundzüge einer Spongien-Fauna des atlantischen Gebietes. (Wilhelm Engelmann: Leipzig): iii-iv, 1-88, pls I-VI

Schulze FE (1885) The Hexactinellida. Pp. 437-451. In: Tizard, T.H., Moseley, H.M., Buchanan, J.Y. \& Murray, J. (Eds), Report on the Scientific Results of the Voyage of H.M.S. 'Challenger', 18731876. Narrative, 1(1)

Schulze FE (1886) Über den Bau und das System der Hexactinelliden. Abhandlungen der Königlichen Akademie der Wissenschaften zu Berlin (Physikalisch-Mathematisch Classe) 1-97

Schulze FE (1887). Report on the Hexactinellida collected by H.M.S. 'Challenger' during the years 1873-76. Report on the scientific results of the voyage of H.M.S. challenger during the years 1873-76. Zoology. 21 (part 53): 1-514, pl. 1-104

Sollas WJ (1885) A classification of the sponges. Annals and Magazine of Natural History. (5) 16(95):395

Tabachnick KR, Reiswig HM (2002) Dictionary of Hexactinellida. In: Hooper JNA, van Soest RWM, Willenz P (eds) Systema Porifera: a guide to the classification of sponges. Springer, Boston, pp 1224 1229

Topsent E (1928) Spongiaires de l'Atlantique et de la Méditerranée provenant des croisières du Prince Albert ler de Monaco. Résultats des campagnes scientifiques accomplies par le Prince Albert I. Monaco. 74:1-376, pls I-XI

Vacelet J (2006) New carnivorous sponges (Porifera, Poecilosclerida) collected from manned submersibles in the deep Pacific. Zool $\mathrm{J}$ Linnean Soc 148:553-584

Vacelet J, Boury-Esnault N (1996) A new species of carnivorous sponge (Demospongiae: Cladorhizidae) from a Mediterranean cave. Bull Inst R Sci Nat Belg Biol 66:109-115

Vacelet J, Kelly M (2014) A new species of Abyssocladia (Porifera, Demospongiae, Poecilosclerida, Cladorhizidae) and other carnivorous sponges from the far eastern Solomon Islands. Zootaxa 3815: 386-396

van Soest RWM, Baker BJ (2011) A new carnivorous shallow-water sponge from McMurdo Sound, Antarctica (Porifera, Poecilosclerida). Mar Biodivers 41:495-501

van Soest RWM, Boury-Esnault N, Hooper JNA, Rützler K, de Voogd NJ, Alvarez B, Hajdu E, Pisera AB, Manconi R, Schönberg C, Klautau M, Picton B, Kelly M, Vacelet J, Dohrmann M, Díaz MC, Cárdenas P, Carballo, JL, Ríos P, Downey R (2020) World Porifera Database. Available from: http://www.marinespecies.org/ porifera/index.php (July 28, 2020)

Zittel KA (1877) Studien über fossile Spongien. I: Hexactinellidae. Abhandlungen der Mathematisch-Physikalischen Classe der Königlich-Bayerischen Akademie der Wissenschaften . München 13(1): $1-63$

Publisher's note Springer Nature remains neutral with regard to jurisdictional claims in published maps and institutional affiliations. 